\title{
Degree of Compliance towards Therapeutic Tasks among Diabetic Patients Attending a Health Insurance Setting In Cairo
}

\author{
Ayman, S. Abd-Elhady* and Abd-El-Aziz, A. El-Sadek** \\ * Public Health and Community Medicine, Assiut Faculty of Medicine, \\ **Public Health and Community Medicine, Cairo Faculty of Medicine, \\ Al-Azhar University
}

\begin{abstract}
Background: Compliance/adherence of diabetic patients towards different therapeutic aspects (other than drugs) is considered one of the most important elements to control diabetes mellitus (DM).

Material and methods: A cross sectional study was conducted on 283 diabetic patients chosen by systematic random sample among those attending Alf-Maskan Health Insurance Outpatients clinics in East Cairo, (from April- May 2007), to assess their compliance behaviors in relation to management of their disease.

Results showed that most of the diabetics $(61.1 \%)$ had a poor total compliance rate for the therapeutic tasks of (DM) as a whole, though the larger proportion of the diabetics (44.9\%) had a satisfactory overall knowledge about the important items of DM. As regards the individual therapeutic tasks, there were also poor compliance rates concerning diet regimen, regular exercise, cessation of smoking, weight monitoring and care of eye and foot. Good compliance rate was significantly higher among patients who were males, highly educated, those of high socioeconomic level, those who had better knowledge about the disease and those who had suffered from multiple co-morbidities and suffered from DM at least ten years.

Recommendations were suggested to improve patient' compliance towards management tasks of the disease through health education program because increasing the information of the patients about the disease and its complications through the shared health care team including the patient himself was valuable.
\end{abstract}

\section{Introduction}

Diabetic mellitus (DM) is a chronic metabolic systemic disease characterized by either a deficiency of insulin or a decreased ability of the body to use insulin. DM was classified as either insulin dependent DM (IDDM) or non insulin dependent DM (NIDDM) (Fain, 2001).

The prevalence of DM is rising all through the world and constitutes a significant public health problem. In United States, about 16.5 million people (5.9\% of the population) have DM; nearly half of them do not know that they have it. Some 3.2 million of the affected persons were 65 years old or more. DM was estimated to be the seventh cause of death in United States with more than 180.000 deaths attributed to the disease in 1995. Even when it does not kill, DM can cause major disabilities, for example, DM is the single greatest leading factor of blindness in adults, end stage of renal failure and non-traumatic amputation (American Diabetic Association, 2003).

In Egypt, DM is a major emerging clinical and public health problem. The total number of diagnosed and non diagnosed cases of DM increased from 3.2 million in 1995 to 3.8 million in 2001 and expected to be 8.8 million in the year 2025 (Shama,1997 and Mohammed, 1999).

Diabetes is a chronic disease of lifelong duration, and its management requires a fundamental change in the patient's lifestyle. For example, Diet therapy is essential in the treatment of all forms of DM and patient is instructed to follow the diet permanently even when there are no symptoms. Adherence to this regimen is essential to reach and maintain ideal body weight, proper nutrition, control blood glucose and lipid levels and 
prevent long and short term complications (Cramer, 2004).

Compliance is defined as the extent of adherence of the patient to medical advice. It is affected by many factors related to the patient, the disease, the physician and the family. The quality of the compliance depends entirely on patient cooperation and understanding of his disease condition and its management (Delamater, 2006).

Frequently, in medicine, compliance and adherence are used as interchangeable terminology. It has been reported that, in general, diabetic patients are nonadherent to their treatment and only a small number of diabetic patients were found adherent or compliant with all aspects of diabetic care (Chatterjee, 2006). The adherence to different aspects of diabetes care has been variable (Martin and Wahren, 1993).

The reasons for poor adherence are multifaceted and complex, but include the characteristics of the individual patients, social and economic factors (Fain, 2001).

Some researchers suggested three solutions to improve poor compliance of diabetic patients: better communication, tailored care and shared care. GPs need communication skills to cope with patients' expectations and evidence based goals in a tailored approach to diabetes care. GPs considered that working in a multi disciplinary team might encourage better compliance/adherence. They believed that dieticians could give more adequate and more varied food advice (Wens et al., 2005).

\section{Aim of the work}

This study was conducted to assess the level of compliance towards different management items (other than drugs) among diabetic patients attending one of the health insurance settings in Cairo city.

\section{Subjects and methods}

A descriptive cross-sectional approach was chosen to investigate compliance/adherence of diabetic patient towards different therapeutic aspects in a health insurance setting. The target population was the diabetic patients attending the diabetic clinic of one randomly selected health insurance outpatient clinics in Cairo (Alf-Maskan Health Insurance Outpatient Clinics in East Cairo). All diabetic patients attending the outpatient clinic during the study period constituted the basis of the sample, from which 283 patients were selected by systematic random sample.

Data were collected (during April and May 2007), using an interview schedule containing the relevant variables:

*Sociodemographic data of the patients including type of DM and duration of the disease as well as knowledge of the patients towards important items of diabetes mellitus.

*The therapeutic behaviors addressed included: compliance with dietary regimen, smoking cessation, physical activity, adherence to periodic checkup (including eye examination and blood pressure measurements), periodic laboratory tests for glucose in blood and urine and self-care practices (foot care, and weight monitoring).

* Scoring system of the knowledge and therapeutic behaviors was used, where the total score was judged as the following: poor (less than 50\% of the correct answers or steps carried out), satisfactory (50\%-75\%) and good (more than 75\%) (Hassanen, 2000).

Administrative and ethical issues including autonomy, confidentiality and informed consent were obtained during all stages of the study. The data collected were analyzed on SPSS program version 13 . Descriptive and analytic statistics were used and the $5 \%$ level or less was considered to be the lowest accepted level of significance.

\section{Results}

Out of total 283 studied diabetic patients, (61.1\%) had a poor total compliance score for the therapeutic tasks of the disease as a whole and (44.9\%) of them had a satisfactory level of total knowledge score about the disease. The 
source of knowledge was multiple (doctors, mass media and other persons) for $(39.6 \%)$ of the diabetics followed by doctors only where mentioned by $(28.3 \%)$ and mass media by $(16.3 \%)$. The ages of the patients were ranging between 25-71 years with mean $\pm S D=47.9 \pm 14.7$ years.

Table (1\&2): The sociodemographic characteristics of the studied sample showed that: most of the sample $(55.1 \%)$ were 41 years old or more, $(55.5 \%)$ were males, about three quarters $(73.1 \%)$ were married, (56.5\%) had intermediate level of education, the greater proportion $(43.1 \%)$ were not working at the time of study and more than two thirds $(68.9 \%)$ were belonging to intermediate socioeconomic standard. As regards data concerning the disease, the majority of the patients $(77.4 \%)$ had Type $2 \mathrm{DM}$ and $(66.4 \%)$ of patients were suffering from DM at least 10 years. Neuropathy was the most common comorbidity where reported by $(35.7 \%)$ of cases followed by hypertension where mentioned by (21.9\%) of them.

Table (3): Elicited the knowledge of the studied patients towards DM items. As regards the total knowledge score towards DM items, it was found that the greater proportion $(44.9 \%)$ of diabetics showed a satisfactory level of knowledge and $(26.5 \%)$ had a good level, while (28.6\%) showed a poor level of knowledge. It was also found that the greater proportion of patients $(48.1 \%)$ thought that DM is the disease of adulthood and (27.2\%) thought that DM may affect both children and adults. With respect to risk factors of $\mathrm{DM},(34.2 \%)$ attributed DM to unbalanced diet, $(27.6 \%)$ reported obesity as a risk factor of DM and (19.8\%) mentioned more than one factor. Neuropathy could be the most common complication according to the patients' point of view where reported by $(31.8 \%)$ of patient and hypertension came second $(20.8 \%)$ of cases.

Table (4): Showed the degree of compliance towards different therapeutic tasks versus the education level of the patients. More than three quarters (77.7\%) of the diabetics adhered poorly to the prescribed diet and only $(8.1 \%)$ adhered to it well. However, $(72.1 \%)$ of the patients usually do not perform any exercise and $(19.1 \%)$ considered their daily routine activities as sufficient physical exercise. The majority $(75.3 \%)$ were still smoking, $(20.8 \%)$ had reduced smoking and only (11\%) had stopped it. Only (13.4\%) perform foot care well, but more than two thirds of the patients $(67.1 \%)$ did that poorly. Most of the studied diabetics $(70 \%)$ showed poor monitoring of their weight, while $(8.6 \%)$ of diabetics monitor their weight well/regularly. A good compliance rate was significantly noticed for all therapeutic tasks (except smoking and exercise) with highly educated studied patients.

Table (5):The lager percentage of the diabetic patients $(45.9 \%)$ were categorized as having a good level of behavior in relation to periodic medical check-up and $(17.7 \%)$ did that with a satisfactory degree. A similar pattern, but to a lesser extent, was observed as regards testing urine for sugar $(36 \%$ did that perfectly and $19.4 \%$ did that satisfactorily) and regular measuring blood pressure where (18\%) showed a good level of practice and $(37.5 \%)$ had a satisfactory degree. Behavior in relation to regular testing blood for sugar needs to be corrected as (55.8\%) of diabetic patients had poor behavior. The majority of patients $(67.5 \%)$ exhibited poor behavior with regard to having regular eye examinations.

Table (6):showed the total compliance score for therapeutic tasks (as a whole) and its relation to some relevant socio-demographic data : sex, duration of the disease, co-morbidity and total knowledge score of the studied diabetics. Those who had a better total compliance score were significantly higher among males (16.6\%) than females $(6.3 \%)$, higher among those who suffered from multiple co-morbidities as (25.5\%) and among those who had better knowledge score about the disease as $(36 \%)$ with highly statistically significant differences, while those who suffered at least ten years from the disease had insignificantly better compliance rate $(13.3 \%)$ than those who suffered a shorter period. 
Table (1): Frequency Distribution of Socio-demographic Characteristics of the Studied Sample.

\begin{tabular}{|c|c|c|}
\hline Characteristics & $\mathrm{N}(=283)$ & $\%$ \\
\hline $\begin{array}{ll}\text { Age (years) } & <31 \\
& 31- \\
& 41+ \\
\text { Mean } \pm \text { S.D. }=47.9 \pm 14.7 \text { (Y.) } & \\
\end{array}$ & $\begin{array}{c}47 \\
80 \\
156\end{array}$ & $\begin{array}{l}16.6 \\
28.3 \\
55.1\end{array}$ \\
\hline $\begin{array}{l}\text { Male } \\
\text { Female }\end{array}$ & $\begin{array}{l}157 \\
126\end{array}$ & $\begin{array}{l}55.5 \\
44.5\end{array}$ \\
\hline $\begin{array}{l}\text { Marital status } \\
\\
\qquad \text { Single/ Divorced / Separate }\end{array}$ & $\begin{array}{c}207 \\
76\end{array}$ & $\begin{array}{l}73.1 \\
26.9\end{array}$ \\
\hline $\begin{array}{l}\text { Illiterate } \\
\text { Intermediate } \\
\text { High }\end{array}$ & $\begin{array}{c}45 \\
160 \\
78\end{array}$ & $\begin{array}{l}15.9 \\
56.5 \\
27.6\end{array}$ \\
\hline $\begin{array}{l}\text { House wife } \\
\text { workers } \\
\text { Not working }\end{array}$ & $\begin{array}{c}53 \\
108 \\
122\end{array}$ & $\begin{array}{l}18.7 \\
38.2 \\
43.1\end{array}$ \\
\hline $\begin{array}{l}\text { Low } \\
\text { Intermediate } \\
\text { High }\end{array}$ & $\begin{array}{c}12 \\
195 \\
76\end{array}$ & $\begin{array}{l}4.2 \\
68.9 \\
26.9\end{array}$ \\
\hline
\end{tabular}

*Based on Fahmy and El-Sherbini, (1983).

Table (2): Frequency Distribution of the Studied Sample According to Type of Diabetes, Duration of the Disease and Concomitant Morbidity.

\begin{tabular}{|c|c|c|}
\hline Item & $\mathrm{N}(=283)$ & $\%$ \\
\hline $\begin{array}{l}\text { Insulin dependent } \\
\text { Non- insulin dependent }\end{array}$ & $\begin{array}{c}64 \\
219\end{array}$ & $\begin{array}{l}22.6 \\
77.4\end{array}$ \\
\hline Duration of the disease (year) & $\begin{array}{c}95 \\
188\end{array}$ & $\begin{array}{l}33.6 \\
66.4\end{array}$ \\
\hline $\begin{array}{l}\text { Associated co morbidity } \\
\qquad \begin{array}{r}\text { Nothing } \\
\text { Cardiovascular (hypertension) } \\
\text { Neuropathy } \\
\text { More than one type } \\
\text { Other health problems* }\end{array}\end{array}$ & $\begin{array}{c}42 \\
62 \\
101 \\
55 \\
23\end{array}$ & $\begin{array}{c}14.8 \\
21.9 \\
35.7 \\
19.5 \\
8.1\end{array}$ \\
\hline
\end{tabular}

*Other problems included : genitourinary troubles, skin infections, eye diseases,... 
Table (3): Frequency Distribution of the Studied Sample According to their Knowledge about Some Important Items of DM.

\begin{tabular}{|c|c|c|}
\hline Item & $\begin{array}{c}\mathrm{N} \\
(=283)\end{array}$ & $\%$ \\
\hline \multicolumn{3}{|l|}{ Total knowledge score } \\
\hline Poor & 81 & 28.6 \\
\hline Satisfactory & 127 & 44.9 \\
\hline Good & 75 & 26.5 \\
\hline \multicolumn{3}{|l|}{ Knowledge about types of DM } \\
\hline I don’t know & 38 & 13.4 \\
\hline Adult onset/ type & 136 & 48.1 \\
\hline Juvenile onset/ type & 32 & 11.3 \\
\hline Both types & 77 & 27.2 \\
\hline \multicolumn{3}{|l|}{ Risk factors of DM } \\
\hline I do not know & 28 & 9.9 \\
\hline Obesity & 78 & 27.6 \\
\hline Hereditary & 24 & 8.5 \\
\hline Unbalanced diet & 97 & 34.2 \\
\hline More than one factor & 56 & 19.8 \\
\hline \multicolumn{3}{|l|}{ Complications of DM } \\
\hline I do not know & 43 & 15.2 \\
\hline Neuropathy & 90 & 31.8 \\
\hline Hypertension & 59 & 20.8 \\
\hline Eye affection & 41 & 14.5 \\
\hline Genitourinary & 21 & 7.4 \\
\hline More than one complication & 29 & 10.2 \\
\hline
\end{tabular}

Table (4):Distribution of the Studied Sample Acording to the Relation Between Educational Level and Therapeutic tasks.

\begin{tabular}{|c|c|c|c|c|c|c|c|c|c|}
\hline \multirow[t]{3}{*}{ Therapeutic tasks } & \multicolumn{6}{|c|}{ Education level } & \multirow{2}{*}{\multicolumn{2}{|c|}{$\begin{array}{c}\text { Total } \\
283 \\
(100.0 \%)\end{array}$}} & \multirow{3}{*}{$\begin{array}{l}\text { Statisti } \\
\text { cal test }\end{array}$} \\
\hline & \multicolumn{2}{|c|}{$\begin{array}{l}\text { Illiterate } \\
45(100.0 \%)\end{array}$} & \multicolumn{2}{|c|}{$\begin{array}{l}\text { Intermediate } \\
160(100.0 \%)\end{array}$} & \multicolumn{2}{|c|}{$\begin{array}{c}\text { High } \\
78(100.0 \%)\end{array}$} & & & \\
\hline & $\mathrm{N}$ & $\%$ & $\mathrm{~N}$ & $\%$ & $\mathrm{~N}$ & $\%$ & $\mathrm{~N}$ & $\%$ & \\
\hline Dietary compliance & & & & & & & & & \\
\hline Poor & 41 & 91.1 & 120 & 75.0 & 59 & 75.6 & 220 & 77.7 & $X^{2}=18.5$ \\
\hline Satisfactory & 3 & 6.7 & 31 & 19.4 & 6 & 7.7 & 40 & 14.1 & $\mathrm{P}=0.001$ \\
\hline Good & 1 & 2.2 & 9 & 5.6 & 13 & 16.7 & 23 & 8.1 & \\
\hline Exercise compliance & & & & & & & & & \\
\hline No exercise & 33 & 73.3 & 113 & 70.6 & 58 & 74.4 & 204 & 72.1 & $X^{2}=2.5$ \\
\hline Daily activities & 9 & 20.0 & 34 & 21.3 & 11 & 14.1 & 54 & 19.1 & $\mathrm{P}=0.06$ \\
\hline Regular exercise & 3 & 6.7 & 13 & 8.1 & 9 & 11.5 & 25 & 8.8 & \\
\hline Smoking & & & & & & & & & \\
\hline Still smoker & 37 & 82.2 & 116 & 72.5 & 60 & 76.9 & 213 & 75.3 & $X^{2}=3.5$ \\
\hline Reduced & 6 & 13.3 & 39 & 24.4 & 14 & 17.9 & 59 & 20.8 & $\mathrm{P}=0.5$ \\
\hline Stopped & 2 & 4.4 & 5 & 3.1 & 4 & 5.1 & 39 & 11.0 & \\
\hline Foot care practices & & & & & & & & & \\
\hline Poor & 34 & 75.6 & 98 & 61.3 & 58 & 74.4 & 190 & 67.1 & $X^{2}=11.0$ \\
\hline Satisfactory & 6 & 11.15 & 42 & 26.3 & 8 & 10.3 & 55 & 19.4 & $\mathrm{P}=0.026$ \\
\hline Good & & & 20 & 12.5 & 12 & 15.4 & 38 & 13.4 & \\
\hline Weight monitoring & & & & & & & & & \\
\hline Irregular & 39 & 86.7 & 105 & 65.6 & 54 & 69.2 & 198 & 70.0 & $X^{2}=17.5$ \\
\hline In-between & 5 & 11.1 & 44 & 27.5 & 11 & 14.1 & 60 & 21.2 & $\mathrm{P}=0.001$ \\
\hline Regular & 1 & 2.2 & 11 & 6.9 & 13 & 16.7 & 25 & 8.6 & \\
\hline
\end{tabular}


Table (5): Distribution of the Studied Sample According to Their Compliance Rate on Seeking Medical Care versus Socioeconomic Level.

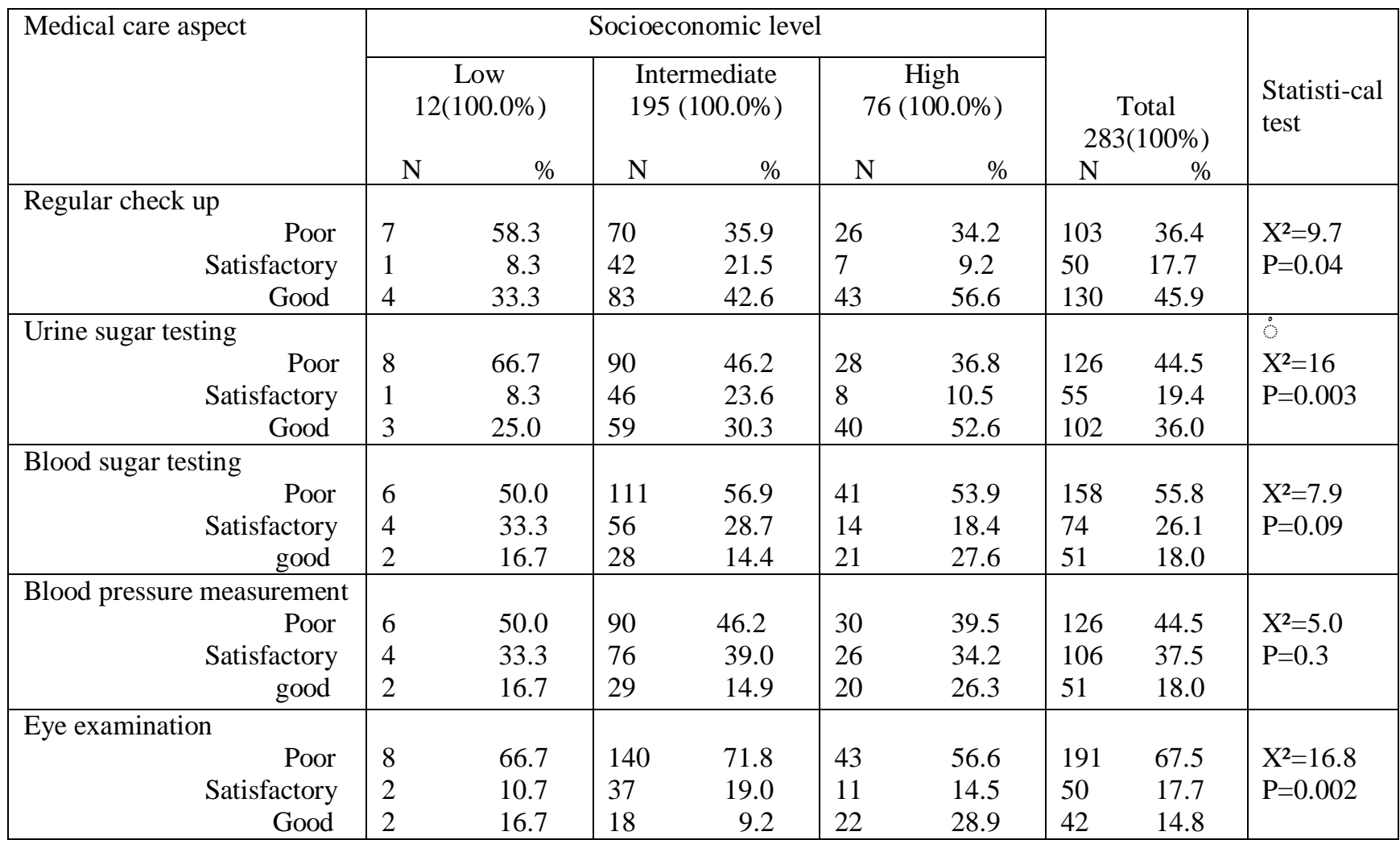

Table (6): Frequency Distribution of the Studied Sample According to Total Compliance Score in Relation to Some Socio-demographic Variables.

\begin{tabular}{|c|c|c|c|c|c|c|c|c|c|}
\hline \multirow{3}{*}{$\begin{array}{l}\text { socio-demographic } \\
\text { variables }\end{array}$} & \multicolumn{6}{|c|}{ Total compliance score } & \multirow{2}{*}{\multicolumn{2}{|c|}{$\begin{array}{c}\text { Total } \\
283(100 \%)\end{array}$}} & \multirow{3}{*}{$\begin{array}{l}\text { Statisti- cal } \\
\text { test }\end{array}$} \\
\hline & \multicolumn{2}{|c|}{$\begin{array}{c}\text { Poor } \\
173(61.1 \%)\end{array}$} & \multicolumn{2}{|c|}{$\begin{array}{l}\text { Satisfactory } \\
76(26.9 \%)\end{array}$} & \multicolumn{2}{|c|}{$\begin{array}{l}\text { Good } \\
34(12.0 \%)\end{array}$} & & & \\
\hline & $\mathrm{N}$ & $\%$ & $\mathrm{~N}$ & $\%$ & $\mathrm{~N}$ & $\%$ & & & \\
\hline Sex & & & & & & & & & \\
\hline Male & 83 & 52.9 & 48 & 30.6 & 26 & 16.6 & 157 & 100.0 & $\mathrm{X}^{2}=11.8$ \\
\hline Female & 90 & 71.4 & 28 & 22.2 & 8 & 6.3 & 126 & 100.0 & $\mathrm{P}=0.003$ \\
\hline $\begin{array}{l}\text { Duration of the disease } \\
\text { (Year) }\end{array}$ & & & & & & & & & \\
\hline$<10$ & 53 & 55.8 & 33 & 34.7 & 9 & 9.5 & 95 & 100.0 & $X^{2}=4.7$ \\
\hline $10+$ & 120 & 63.8 & 43 & 22.9 & 25 & 13.3 & 188 & 100.0 & $\mathrm{P}=0.09$ \\
\hline Co morbidity & & & & & & & & & \\
\hline Nothing & 29 & 69.0 & 12 & 28.6 & 1 & 2.4 & 42 & 100.0 & \\
\hline CVS & 38 & 61.3 & 19 & 30.6 & 5 & 8.1 & 62 & 100.0 & $X^{2}=18$ \\
\hline Neuropathy & 58 & 57.4 & 30 & 29.7 & 13 & 12.9 & 101 & 100.0 & $\mathrm{P}=0.02$ \\
\hline Others & 18 & 78.3 & 4 & 7.4 & 1 & 4.3 & 23 & 100.0 & \\
\hline Multiple & 30 & 54.5 & 11 & 20.0 & 14 & 25.5 & 55 & 100.0 & \\
\hline Overall knowledge score & & & & & & & & & \\
\hline Poor & 49 & 60.5 & 26 & 32.1 & 6 & 7.4 & 81 & 100.0 & $X^{2}=66.7$ \\
\hline Satisfactory & 98 & 77.2 & 28 & 22.0 & 1 & 0.8 & 127 & 100.0 & $\mathrm{P}=0.000$ \\
\hline Good & 26 & 34.7 & 22 & 29.3 & 27 & 36.0 & 75 & 100.0 & \\
\hline
\end{tabular}




\section{Discussion}

Regimen adherence/compliance problems are common in individuals with diabetes, making glycemic control difficult to attain. Because the risk of complications of diabetes can be reduced by proper adherence, patient non adherence to treatment recommendations is often frustrating for diabetes health care professionals (Jeavons, 2006).

The main objectives of management of diabetes mellitus are to improve the quality of life of patients, so that they can have as normal life as possible. Successful management depends upon the extent to which a person's behavior in terms of keeping appointments, taking medication and making lifestyle changes coincides with the medical advice given (Bissell et al., 2004).

Management of diabetes is not restricted to medications and monitoring blood glucose level. It also includes an adjustment of diet and amount of exercise (Watts, 2006).

Diet is considered the backbone of any treatment plan for diabetes mellitus. Dietetic recommendations for patients with type 1 diabetes mellitus and type 2 diabetes mellitus are, in principle, the same (Heisler et al., 2003).

(Table 4) showed that $(77.7 \%)$ of patients complied poorly with their prescribed diet. This study does not agree with the study conducted in Alexandria which revealed that $(59.7 \%)$ of the diabetics complied very well with the prescribed diet (Kamel et al., 1999). They explained that by the long duration of illness; however, Vermeire et al., (2003) reported that patients with a longer history of diabetes were less adherent to their diet.

In a study conducted in Mexico (2003), revealed that the overall frequency of noncompliance was $(39 \%)$. Noncompliance rates were: $(62 \%)$ for dietary recommendations, $(85 \%)$ for exercise, $(17 \%)$ for intake of oral hypoglycemic medication, (13\%) for insulin application, and (3\%) for appointment keeping. Hypertension (plus obesity) was the only factor significantly associated with noncompliance (OR 4.58, CI $95 \% 1.0,22.4, \quad \mathrm{p}=0.02)$. They concluded that the frequency of therapy noncompliance was very high, especially for diet and exercise (Ronquillo et al., 2003).

Exercise is another important part of managing diabetes because it improves insulin action in both types of the disease. A regular program of physical activity helps reduce body weight and decrease glucose intolerance and the occurrence of complications (Mohammed, 1999). In spite of the importance of exercise, only $(8.8 \%)$ of our patients performed exercise regularly and (19.1\%) stated that their daily activities were a substitute to doing physical exercise. In agreement with this result, Kamel et al., (1999) in Alexandria, reported that $(12.7 \%)$ of diabetic patients exercised regularly and Shama, (1997) also reported the poor performance of diabetic patients in this area. They considered poor exercise is a reflection of the lifestyle of Egyptians and concluded that people in general and patients in particular need to understand that daily activities are not considered exercise.

Another risk factor for macrovascular complications is smoking. It has been reported that hypertension and smoking interact to increase the risk of diabetic complications including stroke and heart disease (Cramer, 2004). In our study, most of the diabetics $(75.3 \%)$ were still smoking, while only (11\%) stopped smoking. This was in agreement with the study conducted in Alexandria which showed that only $(30 \%)$ of studied diabetics stopped smoking at the time of study (Shama, 1997).

Ulceration and amputation of the lower extremities are among the most serious complications of diabetes. Several studies suggested that attention to foot care can lower the rate of extremity amputations by 44\%-85\% (Daniel and Jensen 2003 and Kozak et al., 1997). We found that only small proportion of our patients $(13.4 \%)$ performed foot care well, while $(67.1 \%)$ poorly cared their feet, in contrast to $(75 \%)$ of diabetic 
patients of the study conducted in Alexandria who made foot care efficiently(Kamel et al.,1999).

Monitoring weight will indicate whether the diet and exercise programs are successful or not. This is a part of managing obesity (Cocco et al., 2005).In our study only $(8.6 \%)$ of diabetics monitored their weight regularly. This was in agreement with another study which mentioned that only $(27.7 \%)$ of diabetic patients monitored their weight regularly (Kamel et al., 1999).

(Table 5) illustrated that the greater proportion of the diabetics $(45.9 \%)$ were perfectly attending routine check-up in addition to (17.7\%) who did that satisfactorily. Kamel et al., (1999) reported high compliance rate $(97 \%)$ with keeping appointments. They mentioned that: good compliance with keeping appointments is expected as health insurance clinics provide patients with free diabetic medications. It should be noted that results from monitoring the patient's condition can be used to assess the efficacy of therapy and the physician can plan future therapy accordingly (Hughes and Manns, 2000).

Routine testing urine for sugar was made perfectly by (36\%) of cases and satisfactorily by (19.4\%), while majority of the patients (55.8\%) showed a poor behavior as regards routine testing blood for glucose. These results were not in agreement with the study conducted in Alexandria which found that the majority of patients had regularly tested their blood and urine for glucose $(96 \%$ and 94.3\% respectively (Kamel et al., 1999). Other studies indicated that the cost of urine and blood testing kits was considered a barrier by nearly one-third of diabetic patients (Daniel and Jensen, 2003 and Albisser et al., 1995).

Hypertension is a known risk factor of macro-vascular disease in diabetes as retinopathy. Hence, diabetic patients should have their blood pressure checked routinely for prevention or early treatment of the disease (Leichter, 2006). In our study, (18\%) of the diabetics showed a good level of follow up as regards measuring blood pressure and $(37.5 \%)$ did that satisfactorily. The study conducted in Alexandria (1997), indicated that only $(38.7 \%)$ of the studied patients periodically went for blood pressure assessment (Shama, 1997).

Loss of vision from retinopathy can be prevented in the majority of patients provided that the condition is detected early (Delamater, 2006). At the same time, our study found that $(67.5 \%)$ of diabetic patients were poorly attending eye screening. This was similarly obtained by another study in which (62\%) of the diabetics did not screen eye routinely and the study suggested that diabetic health care professionals should enforce the recommendation that diabetic patients must have an annual dilated eye examination (Kamel et al., 1999).

In the present study, most of the studied diabetics $(61.1 \%)$ showed a poor total compliance rate, while only (12\%) had a good compliance rate in (table 6). At the same time, the larger proportion of the studied diabetics (44.9\%) showed a satisfactory level of overall knowledge and $(26.5 \%)$ had a good knowledge score as regards the important items of DM (table 3). The Socio-demographic characteristics of better compliance rate were found to be related to male sex, those who had better overall knowledge score about the disease, those who had suffered from multiple co- morbidities and suffered from the disease at least 10 years. Also better compliance score for most of the individual therapeutic tasks was significantly associated with highly educated diabetics and those of high socioeconomic level (table 4\&5).

These results were nearly corresponding to Hassanen and Fouda, (2003) who found that $(34 \%)$ of diabetics had satisfactory knowledge score and only one quarter had a good score of dietary compliance and the study revealed that patient compliance score was better among those aged 21-30 years, males, workers, those of high educational and social levels and those suffered more than 10 years from the disease but these results were less than what obtained by Khattab et al.,(1999), who detected more than $(80 \%)$ of the sample had a good compliance score for drugs and (40\%) had a good compliance score for diet. As 
regards patients' characteristics, they found no statistical significant differences between dietary compliance and sociodemographic data of the studied patients.

A study conducted in Saudi Arabia in a family practice setting showed that no significant relationship between the various aspects of compliance as regards diet, drugs and appointments and the socio-demographic characteristics of the patients, i.e. age, sex, literacy, employment and marital status, and these results were corresponding to western studies which have found that socio-demographic characteristics had no consistent relationship with compliance in general. For about two-thirds of the diabetic patients in the same study, the compliance rating for appointments was good and for $(80 \%)$ their compliance rating for drugs was good, however, only (40\%) had a good compliance rating for diet (Khattab et al., 1999).

In a study conducted in Hong Kong (1999), the findings indicated that there was no association between diabetes knowledge and compliance. There was a gap between what the patients were taught and what they were actually doing (Chan \& Molassiotis, 1999).

Conclusion and recommendation: The study identified that most of the diabetics $(61.1 \%)$ had a poor total compliance rate for the therapeutic tasks of $(\mathrm{DM})$ and it is recommended that increasing the compliance rate among diabetic patients could be achieved through increasing information about the disease and its complications and this can be given at the time of diagnosis and follow up through health education sessions which should fulfill the social demands and the personal characteristics of the individual patients as well as be appropriate to the educational level and cultural beliefs of the patients.

Also, it is clear that there is a gap between what the patients should do and what they are actually doing in managing their diabetes. Hence, it is recommended that every effort should be made to initiate and promote behavioral change in people with diabetes. To achieve this, an appropriate patient education program should be planned. Further research is needed to reveal determinants of compliance behavior.

\section{References}

1. Albisser AM, Sozzi S, Strack TR (1995): Blood or urine glucose based insulin therapy and control of glycemia. Computer simulation study, Diabetes care, 13(4):393-400.

2. American Diabetes Association (2003): Screening for diabetes. Diabetes Care, 26 (1):S21-S24.

3. Bissell P, May CR, Noyce PR (2004): From compliance to concordance: barriers to accomplishing a re-framed model of health care interactions. Social Science \& Medicine, 58(4):851-62

4. Chan RN \& Molassiotis RN (1999): The relationship between diabetes knowledge and compliance among Chinese with non-insulin dependent diabetes mellitus in Hong Kong Journal of Advanced Nursing 30 (2), 431-438.

5. Chatterjee JS (2006): From compliance to concordance in diabetes, J. Med. Ethics, 32: 507-510.

6. Cocco G, Pandolfi, S Rousson V, (2005): Sufficient Weight Reduction Decreases Cardiovascular Complications in Diabetic Patients with the Metabolic Syndrome .A Randomized Study of Orlistat as an Adjunct to Lifestyle Changes (Diet and Exercise) .Heart Drug, 5:68-74.

7. Cramer JA (2004): A systematic review of adherence with medications for diabetes. Diabetes Care, 27:1218-1224.

8. Daniel JM, and Jensen, JL (2003): Factors in Diabetic Footwear Compliance. Journal of the American Pediatric Medical Association, 93 (6): 485-49.

9. Delamater A.M. (2006): Improving Patient Adherence. Clinical Diabetes, 24:71-77.

10. Fahmy SI and El-Sherbini AF (1983): Determining Simple Parameters for Classification for Health Research. The Bulletin of High Institute of Public Health, 8(5):95-98. 
11. Fain, AJ (2001): Management of clients with diabetes mellitus: Medical, surgical Nursing Clinical Management for Positive Outcomes, Vol. 1, $6^{\text {th }}$ edition, W.B., Saunders Company Philadelphia London New York. St Louis, Toronto Sydney.

12. Hassanen RH and Fouda LM.(2003): Dietary compliance among diabetic patients in diabetic clinic in Assuit university hospital, A.A.M.J, 1(2):111125.

13. Hassanen RH (2000): Health education program for pregnant women on postpartum care for normal delivery. D.NS. thesis, Faculty of Nursing, Assuit University.

14. Heisler M, Vijan S, Anderson RM, Ubel PA, Bernstein SJ, Hofer TP (2003): When do patients and their physicians agree on diabetes treatment goals and strategies, and what differences does it make?Journal of General Internal Medicine, 18(11):893-902.

15. Hughes, D and Manns, B (2000): Patient compliance with drug therapy for diabetic nephropathy C.M.A.J. 30; 162(11): 1553-1558.

16. Jeavons HS (2006): Patients with poorly controlled diabetes in primary care: healthcare clinicians'. Postgraduate Medical J. 82: 347-350.

17. Kamel, NM, Badawy, YA, El-Zeiny NA and Merdan IA (1999): Sociodemographic determinants of management behaviour of diabetic patients. Part I. Behaviour of patients in relation to management of their disease Eastern Mediterranean Health Journal, (5):967-973.

18. Khattab MS, Abolfotouh MA, Khan MY and AlKaldi YM (1999): Compliance and control of diabetes in a family setting, Saudi Arabia. Eastern Mediterranean Health Journal, 5(4):764761.

19. Kozak GP, Rowbothman JL, Gibbons GW (1997): Diabetic foot disease: a major problem.
In: Kazak GP et al., eds. Management of diabetic foot problems, 2nd ed. Philadelphia/London, WB Saunders Company.

20. Leichter SB, (2006): Evaluating The Therapeutic Package for Diabetic Patients: The Whole Exceeds the Sum of Its Parts: Clinical Diabetes, 24:102-104.

21. Martin IK, Wahren J(1993). Glucose metabolism during physical exercise in patients with non-insulin dependent diabetes mellitus. Advances in experimental medicine and biology, 334:221-3.

22. Mohammed AM (1999): Impact of management program for non- insulin dependent diabetic patients. D. NS Thesis, High Institute of Nursing, Assuit University.

23. Ronquillo, LH, Téllez-Zenteno, GF,Espinosa, JG and Acevez, AJ (2003): Factors associated with therapy noncompliance in type-2 diabetes patients, Salud Publica Mix, 45:191-197.

24. Shama ME (1997): Study pattern of compliance behaviour of diabetic patients attending diabetic health insurance clinics in Alexandria [Thesis]. Alexandria, Egypt, University of Alexandria.

25. Vermeire E, Van Royen $\mathbf{P}$, Coenen $\mathbf{S}$, Wens J, Denekens(2003) : The adherence of type 2 diabetes patients to their therapeutic regimens: patients' perspective. A qualitative study. Pract Diabetes Int, 20(6):209-214.

26. Watts, T (2006): Periodontal Treatment and Glycemic Control in Diabetic Patients: the Problem of a Possible Hawthorne Effect J Dent Res 85(4):294-295.

27. Wens J, Vermeire,E , Paul Van Royen, Sabbe B, and Denekens J(2005): General Practitioners' perspectives of type 2 diabetes patients' adherence to treatment: A qualitative analysis of barriers and solutions: BMC Family Practice 6:20-26. 


\section{تحديد مدى الالتزام بالواجبات العلاجية بين مرضى السكرى المترددين على احدى عيادات التأمين الصحى بالثقاهرة}

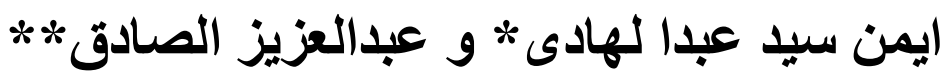

* قسم الصحة العامة وطب المجتمع- كلية الطب- جامعة الأزهر - فرع لهائ

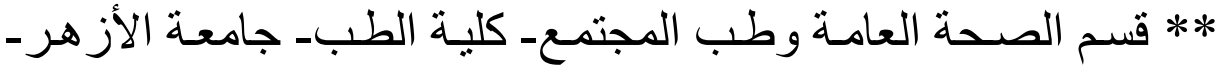

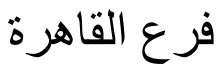

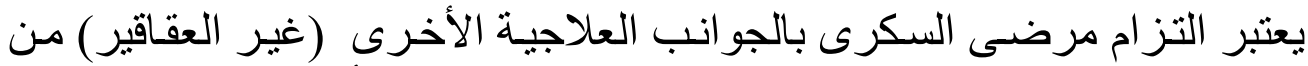

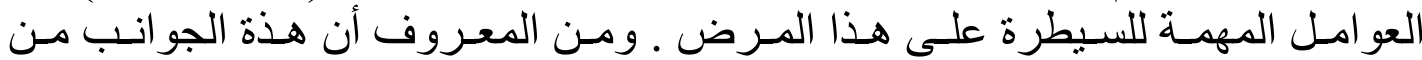

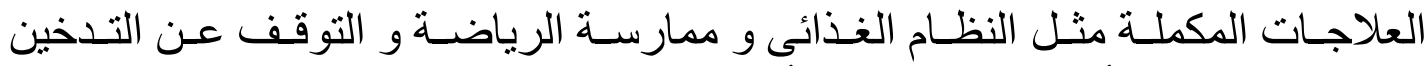

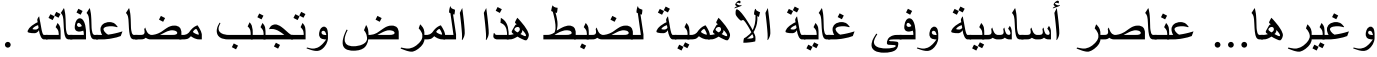

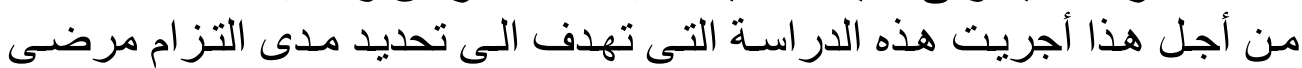

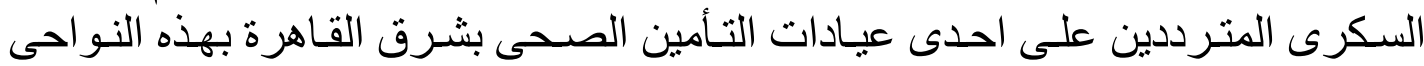

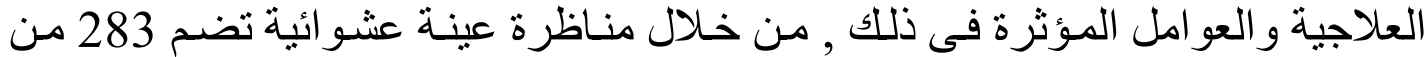

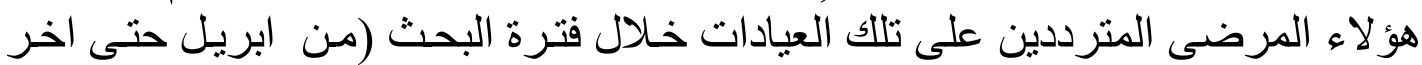

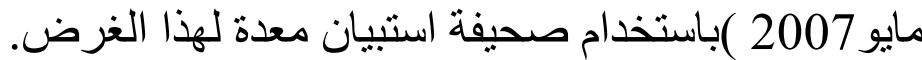

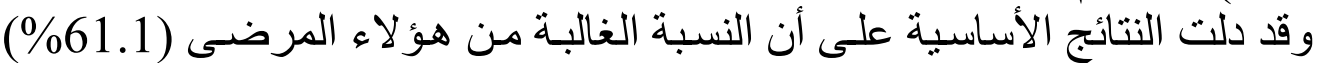

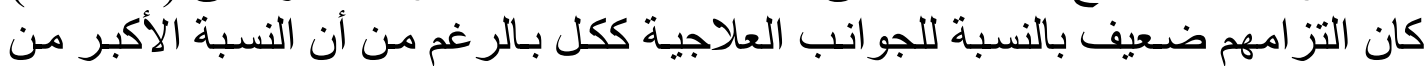

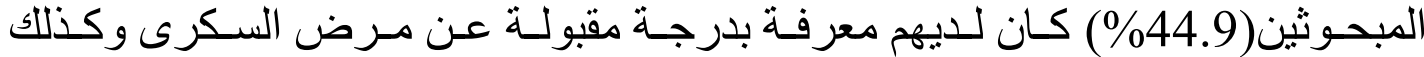

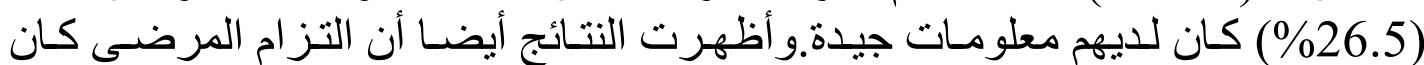

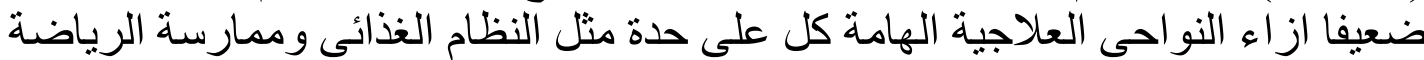

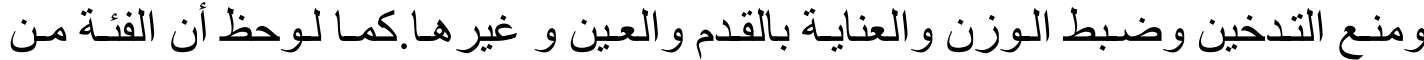

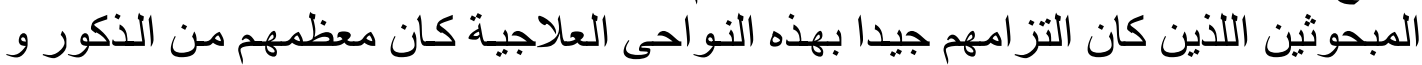

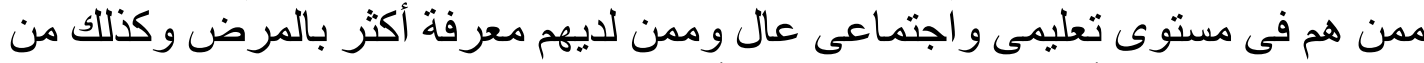

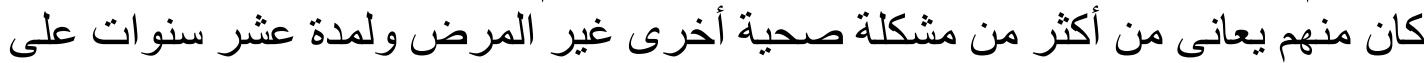

وخلصت الدراسة الى عدد من التوصيات التى قد ترفع من درجة التزام ام المرضىى

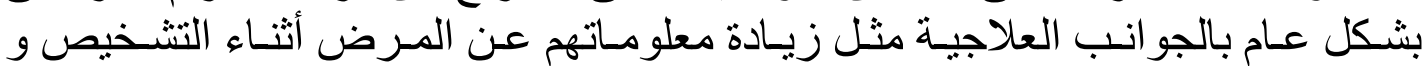

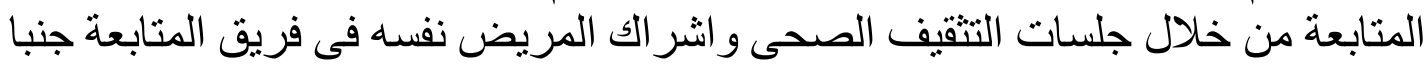
الى جنب مع أخصائى التغذية و ممرضة الصحة العامة بالاضافة الى الطبيب المعالج. 